\title{
The effects of curvature on haptic judgments of extent in sighted and blind people
}

\author{
Morton A Heller, Astrid M L Kappers $\uparrow$, Melissa McCarthy, Ashley Clark, Tara Riddle, \\ Erin Fulkerson, Lindsay Wemple, Anne McClure Walk, Andreana Basso, Crystal Wanek, \\ Kristen Russler \\ Department of Psychology, 119 Physical Sciences Building, Eastern Illinois University, Charleston, \\ IL 61920, USA; e-mail: maheller@eiu.edu; - Helmholtz Institute, Department of Physics of Man, \\ Utrecht University, Princetonplein 5, NL 3584 CC Utrecht, The Netherlands \\ Received 4 August 2005, in revised form 3 September 2007; published online 30 May 2008
}

\begin{abstract}
A series of experiments was carried out to examine the effect of curvature on haptic judgments of extent in sighted and blind individuals. Experiment 1 showed that diameters connecting the endpoints of semicircular lines were underestimated with respect to straight lines, but failed to show an effect of visual experience on length judgments. In experiment 2 we tested arc lengths. The effects of curvature on perceived path length were weaker, but were still present in this experiment. Visual experience had no effect on path length judgments. Another experiment was performed to examine the effect of repeated tracing $(1,5,9$, or unlimited number of traces) on judgments of the lengths of straight lines and diameters of semicircles. Judgments of extent were more accurate when subjects engaged in larger numbers of traces. There was no effect of number of traces on curve-height judgments, suggesting that subjects were not using height estimates to judge diameters of semicircles. In a further experiment we tested the effect of number of traces on curves that varied in height. Restricting subjects to a single trace magnified the effect of path length on judgments of the distance between the endpoints of curves. Additional experiments showed that curvature effects on diameter judgments were not eliminated when stimuli were in the frontal plane or when the curves were explored with the use of two hands. Arm support had no effect on judged length in experiment 7. A final experiment showed a robust horizontalvertical illusion in haptic perception of convex curves, with overestimation of the heights of the curves compared with their widths. The practical and theoretical implications of the results are discussed.
\end{abstract}

\section{Introduction}

The experiments reported here concern haptic perception of the lengths of curved lines and estimates of the shortest distances between their endpoints. While natural and artificial surfaces are often curved, most of us have had relatively little experience in using haptics for the estimation of the lengths of lines, whether curved or straight. There is some indication in the literature that lines connecting endpoints of complex curved paths are often underestimated, but this depends upon scale (Faineteau et al 2003). Underestimation is more likely for larger stimuli. More recently, Faineteau et al (2005) reported that this distortion was diminished when points of inflection were eliminated. Moreover, delay had no effect on the observed error patterns.

Straight lines may often feel curved, and curved lines straight (see Appelle 1991). Haptic perception may be non-Euclidean (Kappers 1999, 2003; Kappers and Koenderink 1999), as in vision (Heelan 1983). Furthermore, visual and/or haptic experience could play a role, since blind subjects performed better than the sighted in judging the curvature of planar solid edges (Davidson 1972). The blind subjects adopted different strategies for feeling curves than the sighted, and this may have prompted their higher levels of performance. According to Davidson, when sighted subjects were instructed to use optimal scanning methods, their performance improved significantly.

Haptic exploration of curved surfaces is known to produce a curvature aftereffect (Gibson 1933). After feeling a curved surface for a few minutes, a subsequently explored flat and straight surface felt curved (see Appelle 1991). However, this sort of aftereffect 
can occur much more rapidly, in as little as $10 \mathrm{~s}$ (Vogels et al 1996, 1997). Clearly, repeated scanning of curves can induce changes in the apparent shape of straight edges. This, in turn, could yield modified percepts of extent. Tracing with the fingertip induces curvature errors (Easton and Falzett 1978).

In the experiments reported here we examined the effect of curvature on judgments of the extents of the lines themselves, of the heights of semicircles and of the diameters of the semicircular lines, and the distances between the endpoints of other curves. One might predict reduced accuracy for judgments of curved as opposed to straight lines, since curves are more complex configurations. Curves have two properties, length and curvature, while a straight line has one. The experiments included blind subjects. Their great reliance on haptics may have boosted their tactile skills. Alternatively, visual experience may be needed to develop haptic expertise with length.

In a number of experiments we sought to find methods to eliminate or moderate the misperception of extent that has been found when feeling curves. The aim was to better understand causal factors influencing the perception of curves. In experiments 1 and 2 we examined the possible influence of visual experience on haptic perception of curved lines in blind and sighted persons. The number of times that subjects traced curves was studied in experiment 3 to determine if this variable was important for accurate judgments of extent. A further experiment was devoted to testing judgments of the heights of curves as a function of the number of times subjects traced the semicircles. The experiment was designed to test the idea that subjects used perceived height information to help them estimate the distance between the endpoints of semicircles. An additional experiment was designed to test the effect of repeated tracing of straight lines and curved lines with varying configurations on judgments of extent. Repeated tracing might produce haptic curvature aftereffects. If so, errors could change, since the percepts of the lines are changing. But are the changes towards greater veridicality of line length, if the lines seem straighter? And would arc judgments increase or decrease in accuracy if a line straightens? Experiment 6 allowed free exploration and also permitted bimanual exploration of the patterns. If tracing represented a nonoptimal exploratory strategy, a different pattern of results could emerge. Finally, stimuli were placed in the frontal plane in experiment 7. The object of this experiment was to eliminate possible distortion of extent in curves due to radial/tangential scanning. Thus, when stimuli are flat on the table surface, tracing the top of a curve involves a tangential motion, while tracing the sides involves motions that converge on the body. Tracing towards the body can yield overestimation of extent in the horizontalvertical illusion (eg Heller et al 1997). In addition, the use of arm support in one group eliminated whole-arm motion and any possibility it could have an effect on haptic judgments. In experiment 8 we sought to determine if the horizontal-vertical illusion occurs with curves, since it occurs with L and inverted-T configurations (see Coren and Girgus 1978).

\section{Experiment 1: Effect of curvature on diameter judgments in blind people}

2.1 Method

2.1.1 Participants. There were three groups of visually impaired participants, including late blind [LB, $n=10$, four females $(\mathrm{F})$, six males $(\mathrm{M})$, mean age $=44.4$ years], very low vision (VLV, $n=10,6 \mathrm{~F}, 4 \mathrm{M}$, mean age $=39.6$ years), and early blind (EB, $n=10$, $6 \mathrm{~F}, 4 \mathrm{M}$, mean age $=49$ years). Detailed information about the subjects can be seen in table 1. The subjects were recruited in Illinois from the communities of Charleston, Champaign, Urbana, Bloomington, Springfield, and Crystal Lake. Most of the subjects were naive to psychological research, and one EB subject did not complete the experiment. This individual claimed that he was unable to make diameter estimates from curved lines, and his data were not included in the analyses reported here. 
Table 1. Characteristics of the visually impaired subjects, including gender, age, education, cause of blindness, age of onset, and presence of light perception.

\begin{tabular}{lllll}
\hline Gender Age/years Education & $\begin{array}{l}\text { Age of onset/ Cause } \\
\text { years }\end{array}$ & $\begin{array}{l}\text { Light } \\
\text { perception }\end{array}$ \\
\hline
\end{tabular}

Early blind

M $\quad 30$

F 32

F $\quad 33$

M 50

M 51

M 52

F 57

F $\quad 58$

F $\quad 62$

F $\quad 65$

$\mathrm{SC}$

HS

JD

MA

JD

HS

HS

BA

SC

unknown

yes

ROP

RP

ROP

ROP

ROP

$\mathrm{RP}$

ROP

meningitis

genetic disorder

no

yes

yes

no

no

minimal

no

BA 0

minimal

yes

\section{Late blind}

F 26

BA

6

ROP,

low vision at birth

no

glaucoma

diabetes

pressure on

optic nerve

diabetes

trauma, shotgun

ROP

accident, glaucoma,

virus

retinal blastoma no

M $\quad 60$

MA

3 or 4

F $\quad 70$

BA

$\mathrm{RP}$, low vision at birth

yes

Very-low vision

M 22

M 28

$\begin{array}{ll}\text { SC } & 0 \\ \text { MS } & 13\end{array}$

F 29

M 36

F $\quad 38$

F $\quad 42$

M 42

F $\quad 47$

MSW 0

SC $\quad 32$

$\begin{array}{ll}\mathrm{SC} & 32 \\ \mathrm{SC} & 30\end{array}$

MA $\quad 36$

MS 25

SC 21

F 51

BA 20

F 61

SG

microphthamia yes

retinal degeneration, yes

low vision at birth

ROP

RP

diabetes

RP

RP

Labers amerosis, low vision at birth retinal detachment retinal degeneration

yes

yes

yes

yes

yes

yes

yes

yes

Note: M, male; F, female; ROP, retinopathy of prematurity; RP, retinitis pigmentosa; SC, some college; SG, some graduate school; HS, high school; JD, law degree; MS, Master of Science, MSW, Master of Social Work.

Sighted subjects $(n=10,4 \mathrm{M}, 6 \mathrm{~F}$, mean age $=37.6$ years, range $=20-65$ years $)$ were recruited on the campus of Eastern Illinois University.

The EB subjects all lost their sight at birth, with the exception of one person who lost vision at the age of 2 years. The LB subjects all lost their sight after 2 years of age. Some of the LB participants had minimal light perception, but were unable to see the direction of strong light sources. None of the blind participants had any visual form perception. The VLV participants were able to see the direction of strong light sources, but most could not see close hand motion. 
2.1.2 Stimuli and apparatus. The stimuli were horizontal tangible lines produced on swell paper (capsule paper). The lines were painted to reduce contrast with the background and ensure that they were invisible to the blind subjects with minimal light perception. The lines consisted of 2.5, 5.1, 7.6, 10.2, and $12.7 \mathrm{~cm}$ straight lines, and curved lines (see figure 1). The curved lines were semicircles that were convex or concave with respect to the top of the page, with diameters of $2.5,5.1,7.6,10.2$, and $12.7 \mathrm{~cm}$. Curved and straight lines were oriented horizontally. Size judgments were obtained with a tangible ruler that has been used in prior studies of haptic illusions (see figure 2, and Heller et al 2002, 2005). The apparatus was oriented so that the ruler faced to the left (from the subjects' vantage point) and could be manipulated by the subjects' left hands. The zero point was located at the body midline. The sighted subjects were blindfolded throughout, as was one of the VLV subjects. Another VLV subject kept his eyes closed throughout the experiment. These two VLV subjects were able to see close hand motion, but could not see the painted tangible lines.

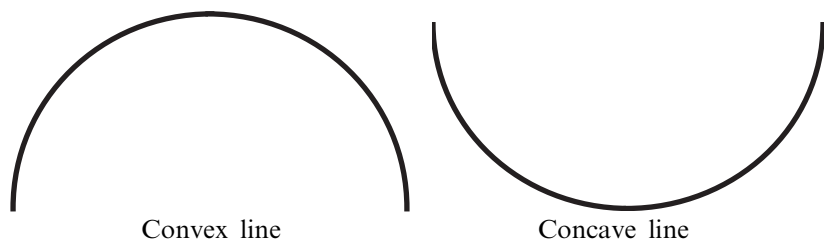

Figure 1. Straight, convex, and Straight control line concave lines.

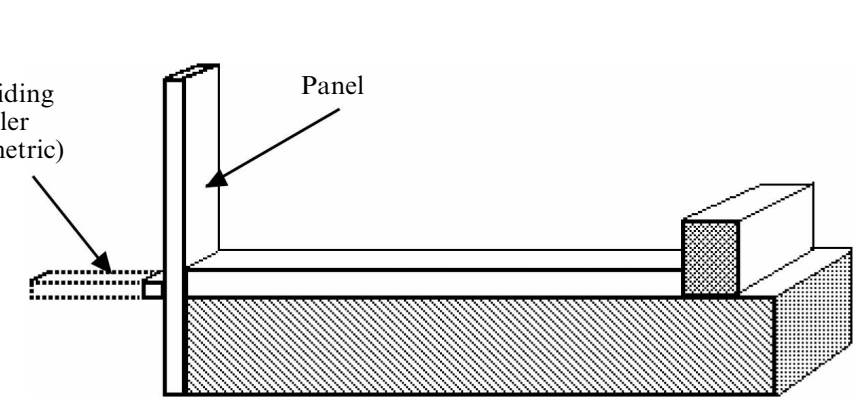

Figure 2. Size estimates made by sliding the bar to the desired length.

2.1.3 Design and procedure. The experiment was a between-within design, with independent groups for the variable of visual status (EB, LB, VLV, BS). Repeated measures were taken on type of line (straight, convex, concave), size (2.5, 5.1, 7.6, 10.2, and $12.7 \mathrm{~cm}$ ) and trials (2). The stimuli were blocked by type of line, and random order of presentation was used for this variable. Subjects had two trials at each level of size and type of line and were exposed to all levels of size within each trial block.

The participants were told to feel the tangible lines with the index fingers of their right hands, and judge the distance between the endpoints using a tangible ruler. They were restricted to the use of their left hands for manipulating the haptic ruler and their right index fingers for feeling the lines. ${ }^{(1)}$ Time limits were not imposed, and subjects

(1) A control experiment was conducted to determine if the hand used to feel or judge stimulus size mattered. Independent groups of right-handed blindfolded sighted subjects attempted the task of judging the diameter between the endpoints of curved lines and the lengths of the straight lines with their left or right hands $(N=20 ; n$ per group $=10)$. The effect of hand failed to reach significance $\left(F_{1,18}=2.83, p>0.10\right)$. None of the interactions with hand were significant, with the interaction between hand and size failing to reach significance $\left(F_{3,54}=2.5, p=0.07\right)$. All of the other interactions with hand yielded $p \mathrm{~s}>0.10$. 
were permitted to alter their size judgments if they wished, and could retrace the lines as many times as they liked.

The participants were instructed to feel the lines and to judge the distance between the endpoints. The judgment of arc length task is described in experiment 2. For the curved lines, they were told to imagine flying the shortest distance possible between the endpoints, and to estimate this extent. They were not allowed to move their fingers off the curved lines when repeatedly tracing them. Feedback on performance was not given.

All subjects were exposed to the diameter judgment task before making judgments of arc length. This sequence was adopted to avoid biasing subjects in their judgments of diameters. It was thought that subjects might spontaneously interpret the task as one involving perception of path length (line length), and we wanted to ensure that there was no lack of clarity in the task instructions. To further explain the task, the problem was demonstrated with the aid of a bent flexible ruler. The experimenter traced the path with one of the index fingers of each of the subjects, and told them to be sure that they judged the distance between endpoints, but not path length.

\subsection{Results and discussion}

Table 2 summarizes the results of the experiments and shows little difference between the groups of visually impaired and sighted participants. There was a tendency to underestimate the distance between the endpoints of curved lines, especially for convex lines. An ANOVA on size estimates showed that the effect of visual status failed to reach significance $(F<1)$, but the effect of type of line did $\left(F_{2,72}=4.16, p<0.2\right)$. Mean judged sizes for the convex, concave, and straight lines were $6.0,6.35$, and $6.65 \mathrm{~cm}$, respectively. A Newman-Keuls test on the means showed that the difference between the straight lines and the convex lines was significant $(p<0.05)$, but the other differences failed to reach significance. All of the interactions with visual status failed to reach significance (all $p \mathrm{~s}>0.20$ ), but the interaction between type of line and stimulus size was highly significant $\left(F_{8,288}=2.36, p<0.02\right)$. Tests of the simple effect of the interaction between type of line and size showed that type of line did not alter judgments for the shortest lines $(F<1)$, or for the longest, $12.7 \mathrm{~cm}$, lines $\left(F_{2,72}=1.3, p>0.25\right)$. However, type of line was significant for all of the other sizes (all $p \mathrm{~s}<0.05$ ). The main effect of stimulus size was highly significant $\left(F_{4,144}=212.81, p<0.001\right)$. The main effect of trials was not significant $(F<1)$, as were all of the other effects (all $p \mathrm{~s}>0.11$ ).

A second ANOVA on signed error scores yielded identical results to the ANOVA on mean size judgments. Mean signed errors for the convex, concave, and straight lines were $-1.60,-1.25$, and -0.95 , respectively. Underestimation of extent was greatest in absolute terms for the longest stimuli $(M=-2.56)$ with a slight overestimation for the shortest lines $(M=0.15)$. The other extents were underestimated. Mean signed error scores for the 5.1, 7.6, and $10.2 \mathrm{~cm}$ lines were $-0.62,-1.34$, and -1.96 , respectively.

Many subjects opted to feel the lines and the ruler simultaneously, and attempted to trace the lines with their right index fingers while tracing the extended ruler with their left index fingers. Subsequently they would shorten or lengthen the ruler to adjust their judgments. Subjects were allowed simultaneous exposure to the stimuli and the ruler on the assumption that this might diminish any errors derived from retention failures. However, it is conceivable that this method may have promoted egocentric coding and perceptual error (see Zuidhoek et al 2003). Time delay may sometimes encourage exocentric coding and greater accuracy. Also, it may be difficult to control exploration with bimanual movements, and this could have caused distortion in perceived extent between the endpoints of the curves. Thus, if one feels a curve with the right index finger, and simultaneously attempts tracing of the straight edge of the ruler, perception of the curve might alter information pickup from the left hand and alter the judgments of extent and configuration. 
Table 2. Mean size judgments of diameter as a function of visual status, line shape and size (with standard deviations in parentheses), including mean signed error scores (with data collapsed over trials) in experiment 1.

\begin{tabular}{|c|c|c|c|}
\hline \multirow[t]{2}{*}{ True size $/ \mathrm{cm}$} & \multicolumn{3}{|l|}{ Stimulus } \\
\hline & convex & concave & control (straight) \\
\hline \multicolumn{4}{|l|}{ Late blind } \\
\hline 2.5 & $2.48(0.95)$ & $2.61(1.3)$ & $2.73(0.95)$ \\
\hline SE & -0.03 & 0.11 & 0.23 \\
\hline 5.1 & $4.20(1.4)$ & $4.25(1.4)$ & $4.46(1.2)$ \\
\hline SE & -0.91 & -0.85 & -0.64 \\
\hline 7.6 & $5.84(1.7)$ & $5.55(1.9)$ & $6.63(2.0)$ \\
\hline SE & -1.77 & -2.06 & -0.97 \\
\hline 10.2 & $8.10(3.0)$ & $7.68(2.2)$ & $8.41(1.8)$ \\
\hline SE & -2.0 & -2.43 & -1.69 \\
\hline 12.7 & $9.65(3.6)$ & $9.76(3.2)$ & $10.62(3.0)$ \\
\hline SE & -3.05 & -2.95 & -2.08 \\
\hline \multicolumn{4}{|l|}{ Early blind } \\
\hline 2.5 & $3.21(1.4)$ & $3.03(0.9)$ & $2.67(0.9)$ \\
\hline SE & 0.71 & 0.53 & 0.17 \\
\hline 5.1 & $4.81(1.7)$ & $5.48(2.2)$ & $4.89(1.9)$ \\
\hline SE & -0.30 & 0.38 & -0.21 \\
\hline 7.6 & $6.12(2.8)$ & $7.68(3.7)$ & $7.29(2.8)$ \\
\hline SE & -1.49 & 0.08 & -0.31 \\
\hline 10.2 & $7.97(3.8)$ & $9.38(4.9)$ & $9.22(3.5)$ \\
\hline SE & -2.13 & -0.73 & -0.89 \\
\hline 12.7 & $9.99(5.3)$ & $11.27(5.6)$ & $11.42(4.8)$ \\
\hline SE & -2.71 & -1.43 & -1.28 \\
\hline \multicolumn{4}{|l|}{ Very low vision } \\
\hline 2.5 & $2.51(1.1)$ & $2.39(1.2)$ & $2.74(0.76)$ \\
\hline SE & 0.01 & -0.11 & 0.24 \\
\hline 5.1 & $3.83(1.8)$ & $3.94(1.6)$ & $4.69(1.0)$ \\
\hline SE & -1.27 & -1.17 & -0.41 \\
\hline 7.6 & $5.45(2.0)$ & $5.61(1.9)$ & $6.50(1.6)$ \\
\hline SE & -2.16 & -1.99 & -1.10 \\
\hline 10.2 & $7.42(2.4)$ & $7.51(2.5)$ & 8.23 (1.6) \\
\hline SE & -2.69 & -2.60 & -1.87 \\
\hline 12.7 & $9.63(3.0)$ & $9.46(3.3)$ & $9.36(1.8)$ \\
\hline SE & -3.07 & -3.25 & -3.34 \\
\hline \multicolumn{4}{|c|}{ Blindfolded sighted } \\
\hline 2.5 & $2.29(0.7)$ & $2.61(0.7)$ & $2.61(0.4)$ \\
\hline SE & -0.22 & 0.11 & 0.11 \\
\hline 5.1 & $3.87(1.3)$ & $4.72(1.6)$ & $4.61(1.2)$ \\
\hline SE & -1.23 & -0.38 & -0.50 \\
\hline 7.6 & $5.29(1.8)$ & $6.44(2.3)$ & $6.77(1.8)$ \\
\hline SE & -2.32 & -1.16 & -0.83 \\
\hline 10.2 & $7.41(3.0)$ & 7.67 (2.9) & $8.67(2.3)$ \\
\hline SE & -2.70 & -2.43 & -1.43 \\
\hline 12.7 & 10.0 & $10.1 \quad(3.3)$ & $10.5 \quad(2.8)$ \\
\hline SE & -2.71 & -2.63 & -2.22 \\
\hline
\end{tabular}

Note: SE, signed error. 
It should be noted that there are a number of ways that subjects may judge extent. For example, they could attempt to locate the endpoints of lines in space, and then compute the distance between them. They could also generate an image of the lines that they feel, and then try to estimate the distance between the endpoints of the imagined configuration. The effect of repeated tracing could be to alter this 'image', but it was not known if repetition would yield increases or decreases in the size estimates. One might expect that, if subjects did not explore the stimuli sufficiently, this could yield erroneous judgments. It was not known if increased tracing would magnify or reduce errors, but it was considered possible that there may be optimal exposure conditions, and this could vary with the stimuli.

In subsequent experiments we explicitly examined the effect of allowing unlimited exposure time, repeated tracing, and the possible influence of simultaneous exposure to the standard stimuli and the tangible ruler.

\section{Experiment 2: Effect of curvature on arc-length judgments in blind people}

The sighted and blind subjects from experiment 1 participated in the second experiment, but this time judged the actual path lengths of straight and curved lines. In all important respects, the method was identical to that of experiment 1 , with the exception of the requirement that subjects judge the lengths of the lines themselves, rather than the diameter between endpoints of the curved lines.

\subsection{Method}

3.1.1 Participants. The same participants who served in the first experiment were involved in experiment 2.

3.1.2 Materials. This experiment used different random arrangements of the conditions of the first experiment, but otherwise the stimuli were similar. The line lengths for the straight-line stimuli were 3.9, 8.0, 11.9, 16.0, and $19.9 \mathrm{~cm}$. The curves were created as semicircles with diameters of $2.5,5.1,7.6,10.2$, and $12.7 \mathrm{~cm}$; path length was identical to that for the corresponding straight lines.

3.1.3 Design and procedure. The procedure was basically like that of experiment 1 . Subjects were instructed to judge the lengths of the lines, rather than the distance between endpoints (for the curves). As in experiment 1, participants made haptic size estimates with the sliding tangible ruler. The sighted subjects were blindfolded throughout, and feedback on performance was not given. Subjects were allowed as much time as they wished to feel the lines and make their size judgments.

\subsection{Results and discussion}

The results of the experiment are shown in table 3 and indicate some distortion of path length (arc length) as a function of curvature. The magnitude of the effect of curvature was diminished relative to diameter judgments in experiment 1. Moreover, visual experience had little impact on size estimates. While the VLV subjects made smaller size estimates $(M$ overall $=10.0 \mathrm{~cm})$ than the other subjects, the effect of visual status failed to reach significance $(F<1)$. The main effect of stimulus size was highly significant $\left(F_{4,144}=468.4, p<0.001\right)$. The main effect of type of line was not significant $(F<1)$, but there were significant interaction effects between line type and size $\left(F_{8,288}=2.3, p<0.02\right)$, owing to shorter judgments for the convex lines, and between type of line and trials $\left(F_{2,72}=3.7, p<0.05\right)$. The interaction between line and size derived from finding that the longest convex lines $(M=15.7 \mathrm{~cm})$ were judged as shorter than the longest concave lines $(M=16.6 \mathrm{~cm})$ and the longest straight lines $(M=16.8 \mathrm{~cm})$. The shortest concave lines $(M=4.5 \mathrm{~cm})$ were also judged as larger than the other lines for the smallest stimuli. The effect of trials was significant for concave lines $(p=0.025)$, with larger size estimates on the second trial. 
Table 3. Mean size judgments of arc length for convex, concave, and straight lines as a function of visual status and size (with standard deviations in parentheses) in experiment 2.

\begin{tabular}{|c|c|c|c|}
\hline \multirow[t]{2}{*}{ True size $/ \mathrm{cm}$} & \multicolumn{3}{|l|}{ Figure } \\
\hline & convex & concave & control (straight) \\
\hline \multicolumn{4}{|l|}{ Late blind } \\
\hline 3.9 & $4.67(2.0)$ & $3.96(1.6)$ & $3.91(1.4)$ \\
\hline SE & 0.77 & 0.06 & 0.01 \\
\hline 8.0 & $7.27(2.8)$ & $7.44(2.8)$ & $7.06(2.4)$ \\
\hline SE & -0.73 & -0.56 & -0.94 \\
\hline 11.9 & $10.16(3.0)$ & $10.15(3.3)$ & $7.99(2.1)$ \\
\hline SE & -1.74 & -1.76 & -2.70 \\
\hline 16.0 & $13.26(4.2)$ & $13.29(3.9)$ & $12.56(3.0)$ \\
\hline SE & -2.75 & -2.72 & -3.45 \\
\hline 19.9 & $15.99(4.6)$ & $16.48(4.3)$ & $15.63(3.6)$ \\
\hline SE & -3.92 & -3.43 & -4.28 \\
\hline \multicolumn{4}{|l|}{ Early blind } \\
\hline 3.9 & $4.57(0.86)$ & $4.97(1.6)$ & $4.15(1.2)$ \\
\hline SE & 0.67 & 1.07 & 0.25 \\
\hline 8.0 & $7.35(2.3)$ & $7.67(2.6)$ & $7.3 \quad(2.2)$ \\
\hline $\mathrm{SE}$ & -0.66 & -0.33 & -0.70 \\
\hline 11.9 & $9.80(2.4)$ & $10.57(3.3)$ & $9.39(2.2)$ \\
\hline SE & -2.10 & -1.34 & -0.79 \\
\hline 16.0 & $13.64(4.3)$ & $12.85(3.8)$ & $14.59(5.0)$ \\
\hline SE & -2.36 & -3.15 & -1.41 \\
\hline 19.9 & $16.04(5.7)$ & $16.06(5.3)$ & $17.60(5.0)$ \\
\hline SE & -3.87 & -3.84 & -2.31 \\
\hline \multicolumn{4}{|l|}{ Very low vision } \\
\hline 3.9 & $3.67(1.0)$ & $4.34(1.4)$ & $3.96(1.1)$ \\
\hline $\mathrm{SE}$ & -0.24 & 0.44 & 0.06 \\
\hline 8.0 & $7.04(1.2)$ & $7.69(2.5)$ & $7.14(1.6)$ \\
\hline SE & -0.96 & -0.32 & -0.86 \\
\hline 11.9 & $9.46(1.9)$ & $10.53(3.4)$ & $8.43(2.2)$ \\
\hline $\mathrm{SE}$ & -2.45 & -1.38 & -2.30 \\
\hline 16.0 & $12.56(2.5)$ & $13.56(3.6)$ & $13.04(3.1)$ \\
\hline SE & -3.45 & -2.45 & -2.97 \\
\hline 19.9 & $14.42(3.2)$ & $16.54(4.2)$ & $15.78(2.4)$ \\
\hline $\mathrm{SE}$ & -5.49 & -3.37 & -4.12 \\
\hline \multicolumn{4}{|c|}{ Blindfolded sighted } \\
\hline 3.9 & $3.90(0.8)$ & $4.68(1.6)$ & $4.20(1.2)$ \\
\hline SE & 0.00 & 0.78 & 0.29 \\
\hline 8.0 & $7.02(1.6)$ & $7.40(2.5)$ & $7.70(1.4)$ \\
\hline SE & -0.99 & -0.61 & -0.30 \\
\hline 11.9 & $10.26(2.5)$ & $9.98(2.6)$ & $9.39(1.6)$ \\
\hline SE & -1.64 & -1.93 & -0.93 \\
\hline 16.0 & $14.69(2.9)$ & $13.66(2.8)$ & $14.48(2.9)$ \\
\hline SE & -1.32 & -2.34 & -1.53 \\
\hline 19.9 & $16.40(3.1)$ & $17.49(3.6)$ & $18.16(3.3)$ \\
\hline SE & -3.50 & -2.41 & -1.74 \\
\hline
\end{tabular}

Note: SE, signed error. 
A second ANOVA on signed error scores yielded similar results. Mean signed error scores for the LB, EB, VLV, and sighted participants were $-1.87,-1.39,-1.98$, and -1.2 , respectively. Mean signed errors were somewhat larger for the convex lines $(M=-1.8)$ than for the concave lines $(M=-1.5)$ or the straight lines $(M=-1.5)$.

Why were convex lines judged as shorter than the other lines? One possibility is that these lines induced motion of the entire arm, but this may not have been as likely for the other lines. Motion of the whole arm can induce illusory misperception in the horizontal-vertical illusion (Heller et al 1997). However, this explanation is unconvincing without further evidence, and subjects did not judge convex and concave lines differently in experiment 3 . This problem is taken up again in experiments 7 and 8.

\section{Experiment 3: The effect of repeated tracing on size judgments of straight lines and diameters of semicircles in blindfolded sighted subjects}

The purpose of experiment 3 was to evaluate the possibility that allowing subjects the option of simultaneously feeling the lines and the ruler could have induced perceptual distortion in judging diameters in experiment 1 . Participants in the present experiment felt the lines, either curved or straight, and then made size estimates from memory. Experiment 3 was intended to test the effect of the number of times that participants traced the tangible lines on judgments of extent for curved and straight lines. Independent groups of subjects were either allowed unlimited numbers of traces, or were instructed to trace the lines once, 5 times, or 9 times. If the underestimation of the diameter of semicircular lines derived from insufficient or excessive tracing in experiments 1 and 2, then one would expect underestimation would vary with the number of times that subjects traced the lines.

\subsection{Method}

4.1.1 Participants. There were four groups of blindfolded sighted participants, with twelve in each group (total $N=48$ ). As in earlier experiments, all of the subjects were right-handed, and half of them were males and half were females. All were naive and had not participated in the other experiments described here.

4.1.2 Materials. The stimuli and apparatus were identical to those of experiment 1 . Blindfolded subjects were exposed to straight lines of 2.5, 5.1, 7.6, 10.2, and $12.7 \mathrm{~cm}$ and curved lines with diameters of 2.5, 5.1, 7.6, 10.2, and $12.7 \mathrm{~cm}$. As in the earlier experiments, a tangible (but not visible) ruler was used for size judgments.

4.1.3 Design and procedure. The experiment was a between-within design, with independent groups for number of times tracing was permitted $(1,5,9$, or unlimited number of times). Repeated measures were taken on length of the stimuli $(2.5,5.1,7.6$, 10.2, and $12.7 \mathrm{~cm}$ ), type of line (convex, concave, straight), and trials (2).

Participants were guided to the right side (from their vantage point) of each tangible line with the aid of a matt board guide that was L-shaped (like a carpenter square). In the 1-trace condition, subjects were told to feel the line just once with the index finger of their right hands, tracing from right to left (from the participant's vantage point). Then the stimulus was removed and they had to adjust the tangible ruler to indicate their estimate of the length of the line (or diameter between endpoints for the semicircles). Subjects were told to trace the line 5 or 9 times as appropriate for those groups. In the unlimited-traces group, participants were instructed to feel the line as many times as they wished before making size estimates with their left hands. They were told that they would not be able to feel the line again once they decided how long it was. In all conditions, tracing started on the right end of the lines and ended when subjects reached the left end. A single trace consisted of a transit from one end of the line to the other. As in the earlier experiments, feedback on performance was not given. 


\subsection{Results and discussion}

The results can be seen in table 4 and indicate that reduced tracing yields more underestimation of lines. This is not what might be expected if one assumes that curvature caused reduced length estimates because of sensory aftereffects intruding on perception (see Gibson 1966). Increases in tracing produced less underestimation of the extent of the diameters of semicircles. An ANOVA on mean size estimates showed a significant effect of number of traces $\left(F_{3,44}=4.43, p<0.01\right)$, a significant effect of type of line $\left(F_{2,28}=5.28, p<0.01\right)$, but a nonsignificant interaction between these two variables $\left(F_{6,88}=1.36, p=0.24\right)$. The main effect of stimulus size was significant $\left(F_{4,176}=91.99, p<0.001\right)$, but the main effect of trials failed to reach significance $(F<1)$. Mean overall size estimates for the 1-trace, 5-traces, 9-traces, and unlimitedtraces groups were 5.3, 5.5, 6.6, and $6.9 \mathrm{~cm}$, respectively. A Newman-Keuls test on these means showed that the unlimited trace and 9-traces conditions were not significantly different $(p>0.05)$, but the unlimited-traces and 9-traces group means were significantly different from the 1-trace and 5-traces groups (all $p \mathrm{~s}<0.05$ ).

The results show that increases in the number of times that subjects traced the curved lines yield improved accuracy of their size estimates, a result that is inconsistent with the notion that something analogous to a haptic curvature aftereffect can explain the underestimation that was found with curved lines in the earlier experiments. However, if increased tracing caused a flattening of the phenomenal curves, then this could yield increased size estimates for the distances between endpoints. This possible explanation is tested in experiment 4 and later in experiment 8. The lack of an effect of trials, or interactions with trials, is also inconsistent with a curvature-aftereffect explanation. The participants judged the diameters of convex lines $(M=6.0 \mathrm{~cm})$ and concave lines $(M=5.9 \mathrm{~cm})$ as shorter than those of straight lines $(M=6.4 \mathrm{~cm})$. A Newman-Keuls test on these means showed that the means for the curved lines were not significantly different from each other $(p>0.05)$, but both means were significantly different from the means for the straight lines (both $p \mathrm{~s}<0.05$ ).

There was a significant interaction between the effect of number of traces and the size of the lines $\left(F_{12,176}=2.57, p<0.01\right)$. Tests of simple effects of this interaction showed that the effect of number of traces failed to reach significance for the shorter $(2.5$ and $5.1 \mathrm{~cm}$ ) stimuli (both $p \mathrm{~s}>0.18$ ), but number of traces was significant for larger stimuli (all $p \mathrm{~s}<0.03$ ). This indicated that tracing was more likely to alter judgments for the longer lines-an outcome that is consistent with other studies (eg Faineteau et al 2003). Also, there was a significant interaction effect between type of line and size $\left(F_{8,352}=2.2, p<0.05\right)$. Tests of simple effects of this interaction indicated that the effect of type of line was significant for all sizes (all $p \mathrm{~s}<0.03$ ), but it was only marginally significant for the $10.2 \mathrm{~cm}$ stimuli $(p=0.056)$ : the effect of type of line was somewhat diminished for $10.2 \mathrm{~cm}$ stimuli, but it is not clear why this occurred. All of the other main effects and interaction effects failed to reach significance (all $p$ s $>0.09$ ).

An ANOVA on signed error scores yielded identical results. As in the analysis of mean size judgments, errors were diminished for the unlimited-traces group $(M=-0.7)$ and 9-traces group $(M=-1.0)$ compared with the 5-traces $(M=-2.1)$ and 1-trace $(M=-2.3)$ groups. Straight lines $(M=-1.2)$ were underestimated less than the diameters between endpoints of convex $(M=-1.7)$ and concave $(M=-1.8)$ lines.

It is very possible that subjects in the unlimited-traces group felt the lines a greater number of times, and this produced less underestimation of the longer lines. Thus, it may be necessary to trace the curves repeatedly to avoid misjudging the diameters between the endpoints of the semicircles. To examine this possibility, the number of times that subjects felt the lines were treated as a dependent measure in a betweenwithin ANOVA for the unlimited-traces group. Subjects traced the straight lines 
Table 4. Mean size judgments of straight lines and the diameters of semicircles as a function of number of traces and size (with standard deviations in parentheses) in experiment 3. Mean signed error scores are collapsed over trials.

True size $/ \mathrm{cm}$

Figure

convex concave control (straight)

One trace

2.5

$\mathrm{SE}$

5.1

SE

7.6

SE

10.2

SE

12.7

SE

$2.60(0.96)$

0.10

$2.41(0.52)$

3.67 (1.09)

$-1.43$

$-0.09$

$2.78(0.66)$

3.86 (1.08)

$-1.24$

0.28

5.14 (2.05)

$-2.46$

6.54 (2.53)

$-3.66$

7.82 (3.27)

$-4.88$

4.96 (1.42)

$-2.64$

4.09 (1.00)

$-1.01$

6.04 (2.21)

$-1.56$

$6.45(2.41)$

$-3.75$

7.48 (3.23)

$-5.22$

7.17 (2.87)

$-3.03$

8.46 (3.38)

$-4.24$

Five traces

2.5

$2.44(0.76)$

$-0.06$

$2.06(0.58)$

$-0.44$

$2.68(0.82)$

$3.53(0.93)$

$-1.58$

3.75 (1.09)

$-1.35$

0.18

5.1

5.13 (1.39)

$-2.47$

5.28 (2.09)

$-2.32$

6.77 (2.33)

6.65 (1.48)

10.2

SE

12.7

SE

8.27 (2.03)

$-3.43$

8.23 (2.73)

$-4.48$

$4.23(0.91)$

$-0.88$

6.18 (1.55)

$-1.42$

7.91 (2.96)

$-2.29$

9.26 (2.67)

$-4.43$

Nine traces

2.5

$2.53(0.64)$

SE

0.03

$2.84(0.64)$

0.34

$2.65(0.68)$

5.1

SE

7.6

SE

10.2

SE

12.7

$4.27(0.84)$

$-0.84$

$4.90(0.78)$

$-0.20$

0.15

4.56 (1.19)

6.54 (1.45)

$6.90(1.30)$

$-1.06$

$-0.70$

$-0.54$

6.35 (1.56)

8.41 (1.92)

$9.10(1.44)$

$-1.10$

$-1.25$

$8.23(2.20)$

9.99 (1.49)

$-1.98$

$-2.71$

10.68 (2.30)

$-1.77$

$-2.03$

\section{Unlimited traces}

2.5
SE

3.02 (1.01)

0.52

$2.88(0.66)$

0.39

$3.23(0.86)$

4.67 (1.40)

$-0.43$

0.73

5.16 (1.63)

0.06

7.00 (2.04)

$-0.60$

6.42 (1.57)

$-1.18$

8.23 (1.90)

$8.75(2.10)$

10.2

SE

12.7

$-1.45$

$-1.98$

5.35 (1.64)

0.25

7.69 (1.74)

0.09

9.59 (2.56)

$9.87(2.33)$

$-0.61$

10.97 (2.56)

SE

$-2.01$

$-2.83$

$-1.73$

Note: SE, signed error. 
more than the semicircles. The main effect of type of line was highly significant $\left(F_{2,22}=5.49, p<0.02\right)$. The mean numbers of traces for the convex, concave, and straight lines were 3.9, 4.1, and 5.2, respectively. A Newman-Keuls test on these means showed that the concave and convex lines both differed significantly from the straight lines $(p<0.05)$, but did not differ from each other $(p>0.05)$. The effect of stimulus size was significant $\left(F_{4,44}=3.5, p=0.015\right)$, but the interaction between size and trials was also significant $\left(F_{4,44}=2.8, p<0.05\right)$. The shorter the line, the fewer times it was traced. Perhaps the subjects are guided by their impressions of absolute size and absolute error. It may require relatively large percentage errors for smaller stimuli to generate noticeable absolute errors. Tests of the simple effects of the interaction between size and trials showed that the effect of size was significant for both trials $(p<0.05)$. The other main effects and interactions all failed to reach significance (all $p$ s $>0.50)$.

The results show that reduced tracing yields increased underestimation of the diameters of curved, semicircular lines. The results of the experiments reported here suggest that, in free-exploration conditions, length judgments are larger compared with cases where subjects trace the lines only once, for example. Moreover, when not constrained, subjects still judge the diameters of semicircles as shorter than they really are. It appears that they do not explore them adequately. They obviously should trace them more than they choose to, since this increased estimates of length and promoted more accurate perception of line length.

\section{Experiment 4: The effect of repeated tracing on judgments of curve height}

Conceivably, the subjects in experiment 3 learned that the curves were all semicircles, and then used height estimates to judge diameters. ${ }^{(2)}$ To test this possibility, two groups of subjects traced semicircles either once or 9 times. If increased tracing yielded changes in subject estimates of diameter because they became better able to judge height, then one might expect improvements in height judgments with more traces. This experiment also allowed us to further evaluate the possibility that increased tracing altered the apparent shape of the curves, for example by flattening them and thereby increasing judged extent at the base. If this occurred, then one might expect substantial changes in judged height as a function of number of traces.

\subsection{Method}

5.1.1 Participants. There were twenty-four blindfolded sighted participants $(8 \mathrm{M}$ and $16 \mathrm{~F})$, with twelve in each group. None served in experiments $1-3$.

5.1.2 Stimuli and apparatus. The stimuli were swell-paper tangible lines like those in experiment 1 . They included convex and concave semicircles, and straight lines with radii (or lengths) of $2.5,5.1,7.6$, and $10.2 \mathrm{~cm}$. The straight lines were oriented vertically, to provide an appropriate control for judgments of the heights of the semicircles. The tangible ruler was oriented so that the ruler could be pulled out in a direction that was perpendicular to the front edge of the table, and radial with respect to the subjects.

5.1.3 Design and procedure. The experiment was a between - within ANOVA, with independent groups feeling each line once or 9 times, but repeated measures were taken on type of line (concave, convex, or straight), size (2.5, 5.1, 7.6, $10.2 \mathrm{~cm})$, and trials (2). Type of line was blocked, but presented in a counterbalanced order. Subjects had 2 trials at each type of line before exposure to another line type. In addition, on each trial, the subjects experienced all sizes of line in an ascending or descending size order. Half of the subjects started with short lines and half started with longer lines; 
this was balanced. The procedure was similar to that of the earlier experiments in other respects.

\subsection{Results and discussion}

The results are shown in table 5 and figure 3 and indicate similar size estimates for the 1-trace $(6.43 \mathrm{~cm})$ and the 9-traces $(7.0 \mathrm{~cm})$ groups. Subjects showed a slight overestimation of the smallest stimuli and underestimation of the largest. A between-within ANOVA revealed a nonsignificant main effect of number of traces on judged curve height $\left(F_{1,22}=1.0, p=0.32\right)$. While the convex lines were judged as somewhat taller than the other lines, the effect of type of line failed to reach significance $\left(F_{2,44}=2.35, p=0.11\right)$, and the interaction between group and type of line also failed to reach significance $\left(F_{2,44}=1.8, p=0.18\right)$. The effect of stimulus size was significant $\left(F_{3,66}=309.8\right.$, $p<0.001)$, but the interaction between size and type of line also failed to reach significance $\left(F_{6,132}=1.9, p=0.09\right)$. None of the other main effects or interactions was significant (all $p$ s $>0.26$ ).

Table 5. Mean size and mean signed errors of height judgments as a function of number of traces, curvature, and size for blindfolded sighted subjects in experiment 4 (with standard deviations in parentheses; data collapsed over trials).

\begin{tabular}{llll}
\hline True size $/ \mathrm{cm}$ & \multicolumn{2}{l}{ Stimulus } & \\
\cline { 2 - 4 } & convex & concave & straight \\
\hline One trace & & & \\
2.5 & $3.65(1.13)$ & $3.33(0.79)$ & $3.74(0.55)$ \\
SE & 1.15 & 0.83 & 1.24 \\
5.1 & $5.61(1.72)$ & $5.26(1.60)$ & $5.43(1.15)$ \\
SE & 0.51 & 0.16 & 0.33 \\
7.6 & $7.63(2.17)$ & $7.28(1.25)$ & $7.30(1.64)$ \\
SE & 0.03 & -0.32 & -0.30 \\
10.2 & $9.40(2.36)$ & $9.23(1.93)$ & $9.25(1.90)$ \\
SE & -0.80 & -0.97 & -0.95 \\
Nine traces & & & \\
2.5 & $4.01(1.56)$ & $4.03(1.16)$ & $3.49(0.92)$ \\
SE & 1.51 & 1.53 & 0.98 \\
5.1 & $6.60(2.50)$ & $5.93(1.45)$ & $5.45(1.02)$ \\
SE & 1.50 & 0.83 & 0.35 \\
7.6 & $8.28(2.07)$ & $8.07(1.89)$ & $7.10(1.29)$ \\
SE & 0.68 & 0.47 & -0.50 \\
10.2 & $11.28(3.59)$ & $10.41(2.64)$ & $8.88(2.05)$ \\
SE & 1.08 & 0.21 & -1.32
\end{tabular}

Note: SE, signed error.

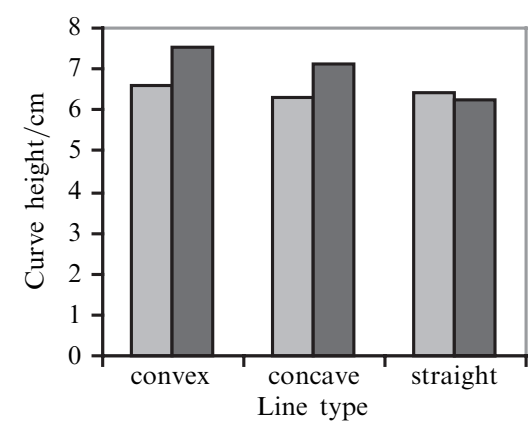

$\square$ one trace

$\square$ nine traces

Figure 3. Lack of effect of number of traces on judged curve height in experiment 4 . 
An ANOVA on signed error scores yielded identical results. While height judgments were slightly larger for the 9-trace group, the ANOVA failed to reveal differences as a function of group or type of line. As in the ANOVA on size estimates, the only significant effect was for stimulus size.

The results of the present experiment are inconsistent with an explanation of the results of experiment 3 that proposes that subjects use judged height to estimate the diameters of semicircles. If that explanation were convincing, subjects in experiment 4 should have changed the size of their height estimates in the 9-traces group. It is conceivable that the increased size estimates for diameter judgments in experiment 3 derived from some distortion in the perceived shape of the curves. The data from experiment 4 can be used to argue against use of height estimates as a component in computation of judged diameter. Clearly, increased tracing did not yield a flattening of apparent curvature, thereby increasing size estimates. This is another argument against a curvature-aftereffect explanation of the data. Experiment 8 was designed to directly test this notion.

\section{Experiment 5: The effect of tracing on judgments of the distance between the endpoints of curves varying in height}

The results of the earlier experiments could be limited to simple curves in a semicircular form. Subjects were repeatedly exposed to convex and concave semicircles and the benefits of repeated tracing could be limited to this very familiar configuration. Consequently, the generality of the results was assessed in experiment 5 by testing subjects with curves varying in configuration. The stimuli consisted of convex semicircles and curves that were increased or reduced in height by $50 \%$ of the diameter of the semicircle. Independent groups of subjects traced lines either once, 9 times, or as many times as they wished. If the improvement found in experiment 3 generalizes to other stimuli, then one might expect more accurate diameter judgments with increases in the number of times that curves are traced.

Allowing the subjects unlimited exposure to the stimuli and providing no constraints on time for making judgments in the earlier experiments may have encouraged some subjects to repeatedly trace the standards. This repeated tracing could induce a curvature aftereffect, since this has been reported in as little as $10 \mathrm{~s}$ of exposure to curved surfaces (Vogels et al 1996, 1997). Personal observation by the first author of this paper suggests that this can occur with lines as well as with surfaces. Introspection revealed that a straight line felt wavy when it was touched after repeatedly tracing a curve. Thus, subjects may have perceived diameters between the endpoints of curved lines as shorter than they really were because of sensory distortion that is analogous to a curvature aftereffect. Curves may prompt altered percepts as they are repeatedly traced within a trial. Also, perhaps there were carryover effects from trial to trial. This experiment was intended to try to test these notions.

\subsection{Method}

6.1.1 Participants. The subjects were thirty blindfolded undergraduates (10M, 20F). None of the subjects served in any of the previous experiments.

6.1.2 Stimuli and apparatus. The stimuli were swell-paper convex curves with distances between the endpoints of $2.5,5.1,7.6,10.2$, and $12.7 \mathrm{~cm}$. The taller stimuli were created with a word processor (Appleworks) by increasing or decreasing the heights of the semicircles by $50 \%$ (see figure 4). Thus, the ratios of height with respect to semicircles consisted of $50 \%, 100 \%$, and $150 \%$, with semicircles at $100 \%$.

6.1.3 Design and procedure. The experiment was a between-within ANOVA, with independent groups for number of traces (1 time, 9 times, unlimited), and repeated measures 


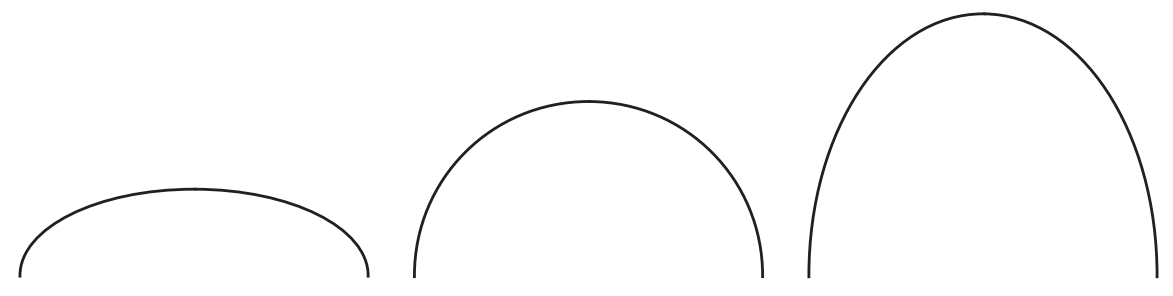

Figure 4. Curves at $50 \%, 100 \%$, and $150 \%$ of the total height with respect to the semicircle. The semicircle is in the middle.

on curvature ratio $(50 \%, 100 \%$, or $150 \%)$, size $(2.5,5.1,7.6,10.2$, and $12.7 \mathrm{~cm})$, and trials (2). Each trial block included judgments of the distance between the endpoints of tangible lines for the three curvature ratios. The order of presentation of the curvature ratios was randomized within each trial block. The procedure was similar to that of experiment 3 in most respects, with the exception of the variation in curvature height. As in the earlier experiments reported here, subjects were blindfolded throughout and were not given any feedback on their judgments.

\subsection{Results and discussion}

The results are shown in table 6 and show an overall underestimation of the distance between endpoints, with the exception of the $2.54 \mathrm{~cm}$ curves. An ANOVA on size judgments showed that the effect of group failed to reach significance $\left(F_{2,27}=2.3\right.$, $p=0.12)$, but the main effect of curvature ratio was highly significant $\left(F_{2,54}=4.1\right.$, $p<0.025)$, owing to smaller judgments for the flatter curves, and larger judgments for the taller, $150 \%$ curves. Path length clearly altered judgments of the distance between endpoints. A Newman-Keuls test on the means indicated that the only significant difference was between the mean for the $50 \%$ and the $150 \%$ curves. However, the interaction between group and curvature ratio was also significant $\left(F_{4,54}=2.8, p=0.035-\right.$ see figure 5). Tests of simple effects of this interaction showed that the effect of group (number of traces) was significant only for the $150 \%$ tall curves $(p<0.05)$, but was marginal for the semicircles $(p=0.057)$. The interaction derived from subjects making much larger mean size estimates with a single trace $(M=7.2 \mathrm{~cm})$ than for unlimited traces $(M=5.3 \mathrm{~cm})$ for the $150 \%$ tall curves (see figure 5). Also, the simple effect of the interaction between curvature ratio and group was significant for the single-trace group $(p<0.01$ ), but not for the other groups (both $p \mathrm{~s}>0.23$ ). This means that tracing just once yielded the greatest difference between judgments for the different curve heights. Also, repeated tracing served to produce underestimation of judged extent.

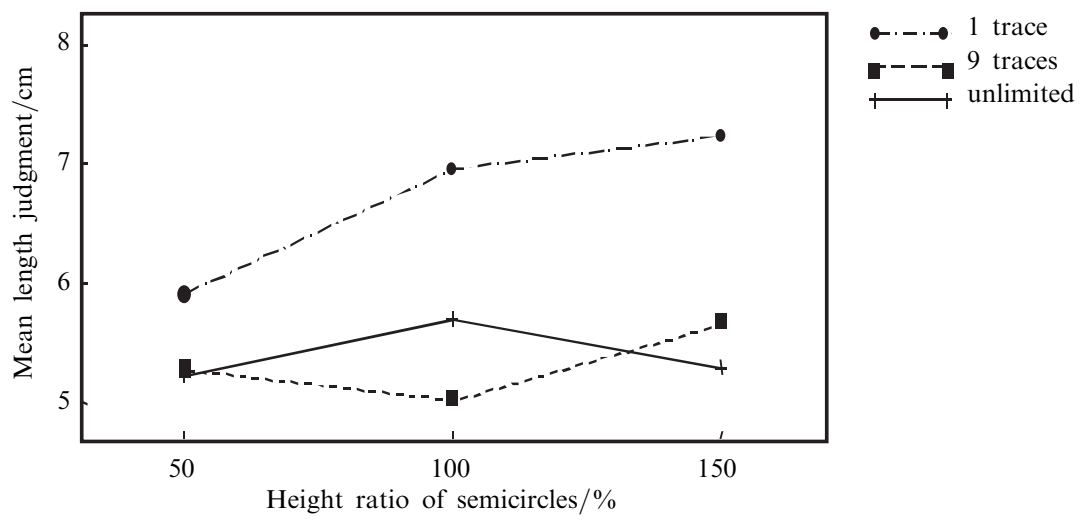

Figure 5. Interaction between height ratio of the curves and judged distance between endpoints in experiment 5. 
Table 6. Mean size judgments of diameters as a function of line height ratio, size, and number of traces for blindfolded sighted subjects in experiment 5 (with standard deviations in parentheses, including mean signed error scores; data collapsed over trials).

\begin{tabular}{|c|c|c|c|}
\hline \multirow[t]{2}{*}{ True size $/ \mathrm{cm}$} & \multicolumn{3}{|c|}{ Curve height ratio } \\
\hline & $50 \%$ & $100 \%$ & $150 \%$ \\
\hline \multicolumn{4}{|l|}{ One trace } \\
\hline 2.5 & $2.41(0.53)$ & $2.83(0.95)$ & $2.99(1.23)$ \\
\hline SE & -0.10 & 0.33 & 0.49 \\
\hline 5.1 & $4.13(1.26)$ & $4.76(2.33)$ & $5.33(1.94)$ \\
\hline SE & -0.97 & -0.34 & 0.23 \\
\hline 7.6 & $5.93(1.43)$ & $7.23(3.05)$ & $7.45(2.60)$ \\
\hline SE & -1.68 & -0.37 & -0.15 \\
\hline 10.2 & $7.60(1.90)$ & $9.23(4.91)$ & $9.20(3.71)$ \\
\hline SE & -2.61 & -0.97 & -1.01 \\
\hline 12.7 & $9.40(2.96)$ & $10.63(4.45)$ & $11.20(5.62)$ \\
\hline $\mathrm{SE}$ & -3.30 & -2.07 & -1.50 \\
\hline \multicolumn{4}{|l|}{ Nine traces } \\
\hline 2.5 & $2.01(0.40)$ & $2.10(0.48)$ & $2.62(0.69)$ \\
\hline SE & -0.49 & -0.41 & 0.12 \\
\hline 5.1 & $3.51(0.91)$ & $3.57(0.62)$ & $4.10(1.09)$ \\
\hline SE & -1.59 & -1.54 & -1.00 \\
\hline 7.6 & $5.26(0.98)$ & $4.65(0.97)$ & $5.42(1.08)$ \\
\hline SE & -2.34 & -2.96 & -2.19 \\
\hline 10.2 & $6.83(1.48)$ & $6.76(0.97)$ & $7.22(1.78)$ \\
\hline $\mathrm{SE}$ & -3.37 & -3.44 & -2.98 \\
\hline 12.7 & $8.82(2.30)$ & 8.09 (1.61) & $9.00(2.27)$ \\
\hline $\mathrm{SE}$ & -3.88 & -4.62 & -3.71 \\
\hline \multicolumn{4}{|c|}{ Unlimited traces } \\
\hline 2.5 & $2.52(0.75)$ & $2.61(0.72)$ & $2.73(0.92)$ \\
\hline SE & 0.02 & 0.11 & 0.23 \\
\hline 5.1 & $3.71(1.13)$ & $4.36(1.41)$ & 4.19 (1.41) \\
\hline SE & -1.39 & -0.74 & -0.92 \\
\hline 7.6 & $4.99(0.98)$ & $6.09(1.88)$ & $5.29(1.93)$ \\
\hline SE & -2.62 & -1.52 & -2.31 \\
\hline 10.2 & $6.61(1.39)$ & $7.21(1.66)$ & $6.57(2.16)$ \\
\hline $\mathrm{SE}$ & -3.59 & -2.99 & -3.64 \\
\hline 12.7 & $8.21(1.4)$ & $8.17(2.08)$ & $7.84(2.64)$ \\
\hline SE & -4.50 & -4.54 & -5.13 \\
\hline
\end{tabular}

Note: SE, signed error.

An ANOVA on signed error scores yielded similar results, with a nonsignificant main effect of group $\left(F_{2,27}=2.6, p=0.09\right)$, but underestimation appeared greater with unlimited traces $(M=-2.54)$ than with 1 trace $(M=-0.9)$. In general, the results of the ANOVA on signed error scores were similar to those for size estimates, but there was a significant interaction between group and curvature ratio $\left(F_{4,54}=4.9\right.$, $p<0.01)$. Tests of the simple effects of this interaction showed that the effect of curvature ratio failed to reach significance for the 9-traces group $(p=0.20)$, but was highly significant for both other groups (both $p$ s $<0.01$ ). This means that changes in curvature ratio failed to alter judgments of the distance between the endpoints of curves, given sufficient tracing.

An examination of signed error scores in table 6 indicates that there is actually more underestimation of the distances between endpoints in the $50 \%$ conditions than in the $150 \%$ conditions, for the single-trace group. These results suggest that alterations in path length can generate misperception, given reduced tracing. 
We counted the number of times that subjects in the unlimited-traces group opted to trace the curves. The mean number of traces for the $50 \%, 100 \%$, and $150 \%$ groups were 3.62, 3.58, and 3.64, respectively. The effect of curvature height on number of traces was not significant $(F=0.16)$.

Increases in the number of traces did not always aid subjects as they attempted to estimate path completion for the larger stimuli in this experiment, unlike in experiment 3. It is likely that the variation in curvature contributed to this failure. Regularity is a clear aid to perceptual accuracy, and uncertainty is likely to reduce performance. Increased tracing actually lowered accuracy, since the mean signed error scores were reduced for single tracing of semicircles compared with repeated tracing in the present experiment.

The results are also inconsistent with the idea that curvature aftereffects alone could fully explain distortion in estimating diameters in the earlier experiments. Additional research will be needed to clarify these effects, as they are complex. However, a curvature-aftereffect explanation of the results of this experiment should lead one to predict that the present effects of tracing would not be found if one were to run independent groups for curve-height ratios. In the third experiment, increased tracing improved perceptual accuracy and led to a reduction in underestimation of diameters. This only occurred for the smallest stimuli in the present experiment. Moreover, increased tracing had no effect on judged curve height in experiment 4 . Thus, a curvature aftereffect alone is unlikely to explain the results of the earlier experiments reported here. Other possible mechanisms are taken up in subsequent experiments.

\section{Experiment 6: Bimanual exploration of semicircles and arc length judgments}

One might argue that if method of exploration matters, then illusory misperception of curves could derive from an artificially constrained exploration strategy. On this view, the underestimation of longer curved lines that was obtained in many of the experiments reported in this study could be related to the choice of a nonoptimal method for feeling the stimuli, and this method was imposed by the experimenter. Participants in the earlier experiments reported here traced lines with the index fingers of their right hands. The subjects in experiment 6 were asked to judge the lengths of the lines themselves, just as in the second experiment. Many blind subjects in experiment 2 objected to the use of a single index finger to feel the curved and straight lines, and it was expected that the ability to use the fingers of two hands would aid perceptual accuracy. Using two hands and multiple fingers could help subjects by providing spatial reference information, or by simply allowing more skilled exploration. The Müller-Lyer illusion was practically eliminated when participants used the index fingers of two hands to examine the stimuli (Heller et al 2005).

To evaluate the possibility that restricting subjects to the use of a single index finger contributed to the results of the earlier experiments reported here, a group of subjects felt concave and convex semicircles, but they were allowed to feel them with both hands and use any method that they wished. As in the earlier experiments, they were restricted to the use of their left hands to adjust the tangible ruler. If the results of the earlier experiments were limited to tracing with a single finger of the right hand, one should not see underestimation of larger stimuli, nor should there be a difference between the length judgments of curves as opposed to straight lines.

\subsection{Method}

7.1.1 Participants. There were twelve naive subjects $(7 \mathrm{~F}, 5 \mathrm{M})$ in this experiment. All were right-handed sighted undergraduates and blindfolded throughout. 
7.1.3 Procedure. The participants were told that they could use two hands if they wished to feel the patterns, but could only use their left hands for adjusting the haptic ruler. They were also told that they should always keep at least one finger in contact with the stimulus at all times. In other respects the procedure was like that of the earlier experiments. No restrictions were placed on the number of times that the subjects were allowed to trace the lines, if they chose to use tracing. Also, they were permitted to use multiple fingers to feel the tangible stimuli, and with both hands if they wished.

\subsection{Results and discussion}

Overall, the subjects made similar size estimates of the convex $(M=10.5 \mathrm{~cm})$, concave $(M=11.1 \mathrm{~cm})$, and straight lines $(M=11.5 \mathrm{~cm})$. An ANOVA on absolute-size judgments yielded a nonsignificant main effect of type of line $\left(F_{2,22}=1.6, p>0.05\right)$, but a significant interaction effect between type of line and stimulus size $\left(F_{8,88}=2.32\right.$, $p=0.026)$ owing to underestimation of the larger curves. The results were very similar to those of experiment 2. This means that the results of earlier experiments were not limited to the use of tracing with the index finger, or to some difficulty arising from use of the right hand to feel the stimuli and the left hand for size estimates. Thus, the results generalized to conditions where there were no constraints on the manner of exploration of the stimuli.

An ANOVA on signed error scores had similar results and the effect of trials also reached significance $\left(F_{1,11}=6.8, p<0.025\right)$. The interaction between size and trials was also significant $\left(F_{4,44}=5.4, p<0.01\right)$. Generally, the subjects overestimated the shortest stimuli, and underestimated the longest, and the underestimation diminished from the first to the second trial. The interaction between type of line and size derived from greater underestimation of the longest $19.9 \mathrm{~cm}$ convex semicircle $(M=-4.2 \mathrm{~cm})$ and the longest concave line $(M=-3.1 \mathrm{~cm})$, as compared with the longest straight line $(M=-1.7 \mathrm{~cm})$.

\section{Experiment 7: Lack of an effect of arm support on judgments of diameters of semicircles in the frontal plane}

Upon the completion of experiment 6, we asked subjects to describe the shapes of the contours that they felt. Some of the subjects described the semicircles as U-shaped. They then drew a similar shape under normal viewing conditions. However, some individuals drew horseshoe configurations, with the ends closer together than one would find in an inverted-U shape. A few drew rather distorted images (see figure 6). Clearly, there are large individual differences in this area.

Perhaps changes in the trajectory and direction of scanning motions could alter the apparent shapes of the curves. The outside of convex semicircles would yield radial motions towards the body in the present experiment, while the tops of the curves would not. Radial scanning has been linked to overestimation of verticals in inverted-T shapes, ie the horizontal-vertical illusion. Radial movements towards the body are generally overestimated relative to tangential movements that do not converge upon the body. Judgments of extent are altered when stimuli are in the frontal plane, and Heller et al (2003) found a negative horizontal-vertical illusion when the vertical segment of inverted-T figures was gravitationally vertical. The horizontal-vertical illusion could play a role in judgments involving curves (eg the St Louis Arch, see Coren and Girgus 1978; Heelan 1983). Thus, it was expected that frontal placement should reduce illusory misperception of the diameters of semicircles, since the placement would eliminate any possible contribution of radial or tangential scanning effects.

In experiment 7 we examined the effect of arm support and placement in the frontal plane on judgments of curvature. Placement in the frontal plane conceivably could alter judgments by reducing perceptual error (see Heller 1992). Note, too, that Faineteau et al 

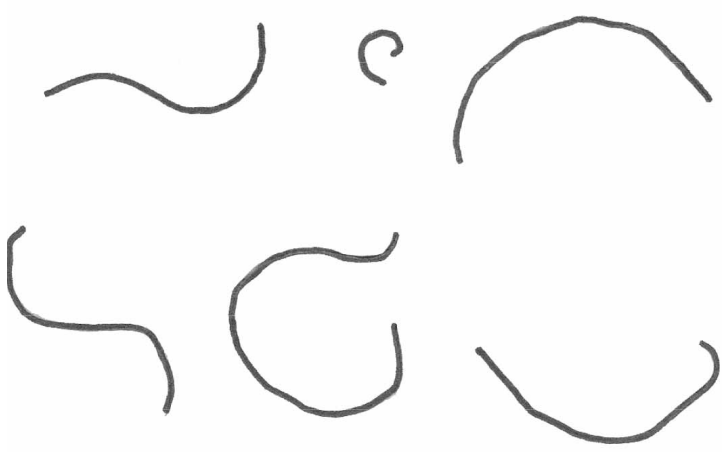

Figure 6. Some of the drawings of the curves made by a few of the subjects after completion of experiments 6 and 7 .

(2005) reported that in frontal placement, downward tracing yielded different rates of exploration than upward tracing. However, they failed to find any effect of frontal placement on judgments of extent. Their stimuli were oriented so that the distance between the endpoints of the stimuli was vertical (Faineteau et al 2005). In the present experiment, subjects in one group traced patterns while their right arms were supported by a board. The other subjects traced concave, convex, and straight lines without this arm support. The reduction in whole-arm motion was expected to reduce perceptual error (see Heller et al 1997). This followed from the assumption that motions of the entire arm are likely to increase perceptual distortion.

\subsection{Method}

8.1.1 Participants. There were twenty-six naive, right-handed, blindfolded sighted subjects in experiment $7(6 \mathrm{M}, 7 \mathrm{~F}$ in each group).

8.1.2 Stimuli and apparatus. The stimuli were identical to those of experiment 3. The novel aspect of this experiment was that the stimuli were placed in the frontal plane and held there on a clipboard fastened to the front of the shelf holding the tangible ruler. The entire apparatus was moved close to the front edge of the table. For subjects in the group with arm support, a rectangular wooden board was clamped to the table surface to support the subjects' right arms as they felt the stimuli with their right index fingers.

8.1.3 Design and procedure. The experiment was a between - within design, with independent groups for arm support (no support versus support), and repeated measures were taken on type of line (concave, convex, straight), size $(2.5,5.1,7.6,10.2$, and $12.7 \mathrm{~cm}$ ) and trials (2). In most respects, the experiment was conducted very much like the 1-trace condition in experiment 3, and participants judged the distance between the endpoints of semicircles and the lengths of straight lines. Subjects were told that they were to make 1 trace of the stimulus with the index finger of their right hands, and they were to use their left hands to make size judgments after they completed their trace. They traced from the right side of the stimuli to the left before making estimates of extent. In the group with arm support, subjects were told not to lift their arms off the surface of the board. In addition, they were told that the purpose of arm support was to determine if this aided perceptual accuracy. Feedback on responses was not given.

\subsection{Results and discussion}

Diameter judgments for the arm-supported group $(M=5.2 \mathrm{~cm})$ were smaller than for the unsupported group $(M=5.9 \mathrm{~cm})$. An ANOVA on mean size judgments yielded a nonsignificant effect of group $\left(F_{1,24}=2.6, p=0.12\right)$. The effect of type of line was highly significant $\left(F_{2,48}=30.5, p<0.001\right)$ as was the effect of size $\left(F_{4,96}=256.9\right.$, $p<0.001)$. Convex lines $(M=5.1 \mathrm{~cm})$ yielded similar diameter judgments as the 
concave lines $(M=5.0 \mathrm{~cm})$, but both were judged as significantly shorter $(p<0.01)$ than the straight lines $(M=6.6 \mathrm{~cm})$. There was also a significant interaction effect between line and size $\left(F_{8,192}=6.0, p<0.001\right)$, owing to greater effects of curvature as the stimuli increased in size. This is consistent with other reports on the effect of scale (eg Faineteau et al 2005). There was also a significant interaction effect between size and trials $\left(F_{4,96}=3.0, p=0.02\right)$. Tests of simple effects on this interaction yielded nonsignificant effects of trials for all sizes (all $p$ s $>0.16$ ), but the effect of size was significant for both trials (all $p \mathrm{~s}<0.01$ ). The interaction derived from much more accurate size estimates for the smallest stimuli on the second trial $(M=2.56 \mathrm{~cm})$ than on the first trial $(M=2.95 \mathrm{~cm})$. None of the other main effects or interaction effects reached significance (all $p \mathrm{~s}>0.099$ ). A second ANOVA on mean signed error scores showed essentially the same results.

Another ANOVA was conducted, but included the 1-trace group from experiment 3 and the two groups of the present experiment. This group of subjects had the stimuli flat on the table surface. The effect of group failed to reach significance $\left(F_{2,35}=1.1\right.$, $p=0.33$ ) indicating a lack of an effect of the frontal placement on size estimates. However, as expected, the effect of type of line was highly significant $\left(F_{2,70}=31.2\right.$, $p<0.01)$. The effect of size was highly significant $(p<0.01)$, as were the interactions between line and size $(p<0.01)$ and size and trials $(p<0.05)$. The results were consistent with a similar outcome reported by Faineteau et al (2005), even though these authors had their stimuli oriented so that diameters were vertical. It bears repetition that the subjects in the present experiment judged the diameters of curves, and these extents were horizontal.

The effects of stimulus placement and arm support failed to reach significance, but future work in this area is clearly called for. Some subjects showed rather dramatic distortion of size in their underestimations of diameters, and there were large individual differences in performance. Also, the controls provided on arm support were merely instructional. Some subjects could have strained their arms as they explored the stimuli, even though this may not have been obvious to the experimenter. The support variable needs to be more carefully manipulated in future research, perhaps with physical constraints (see Heller et al 1997). Furthermore, stimulus variables may be important, and rather different results could be obtained for stimuli like those used in experiment 5 . This will be the subject of additional research that is planned.

\section{Experiment 8: Curves and the haptic horizontal - vertical illusion}

The vertical is often overestimated with respect to horizontals when verticals generate radial scanning motions that converge upon the body (Heller et al 2003). This overestimation of verticals could occur with convex curves and thereby produce length distortion. Recall that some subjects in earlier experiments described the semicircles as U-shaped during debriefing. This could have derived from a horizontal-vertical illusion, with overestimation of the height of the curve. Consequently, in this experiment we asked subjects to make size estimates of the height and width of curves and L shapes. One group of subjects made all their estimates with the horizontal ruler that was used in the earlier experiments reported here, while a second group had two rulers: one oriented radially (vertically) for vertical judgments and a second, horizontal ruler for judgments of the widths of the patterns. The experiment was also designed to examine the possibility that using a single horizontal ruler could yield distorted judgments of pattern height, since the height represented a vertical extent and the ruler was horizontal. Of course, it is possible that subjects could underestimate the distance between the endpoints of curves because they perceive the entire pattern as smaller than it really is. The present experiment was designed to rule out this possibility. It was expected that as with vision (see Coren and Girgus 1978; 
Heelan 1983), touch would show a horizontal-vertical curvature illusion. Subjects were expected to show overestimation of the heights of curves compared to their widths, even though the two were physically identical.

\subsection{Method}

9.1.1 Participants. There were two groups of blindfolded sighted participants with twelve subjects in each group (5M,7F in each), and a total $N$ of 24 .

9.1.2 Stimulus and apparatus. The stimuli were curves and $\mathrm{L}$ shapes with equal heights and widths of $2.5,5.1,7.6,10.2$, and $12.7 \mathrm{~cm}$ (see figure 7). The height and width of each size of tangible swell-paper stimulus were identical. Subjects used a radially (vertically) oriented ruler for height judgments for one group. The radial/vertical ruler was mounted beneath the shelf that held the horizontal ruler from the earlier experiments. This arrangement allowed the subjects in the two-ruler group to make their width judgments with a horizontal ruler and their height judgments with a vertically oriented ruler.
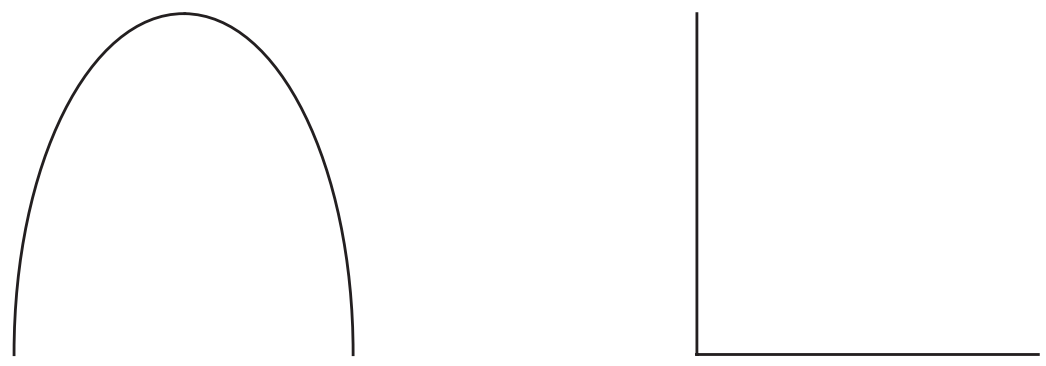

Figure 7. The curve and L shape used to examine the presence of the horizontal-vertical illusion in tangible curves. The height of the curve is equal to the width.

9.1.3 Design and procedure. The experiment was a between-width design, with independent groups for ruler (horizontal ruler, or horizontal and vertical ruler), but repeated measures were taken on type of line (curve or L shape), orientation (horizontal/width and vertical/height), size (5), and trials (2). The subjects were told that they would make size judgments with a tangible ruler, and were to judge the height and width of tangible patterns on swell-paper. Type of line was blocked, but the order of presentation of the stimuli was randomized. Subjects made two judgments about each stimulus on each trial; half of the subjects judged the height first and then the width, while the rest used the reverse sequence.

One group of subjects was limited to the horizontal tangible ruler for their height and width judgments, while the second group of subjects used a vertical ruler for vertical judgments and a tangible horizontal ruler for width judgments. The subjects used their right index finger to trace the stimuli and their left hands for size estimates. They were able to feel the stimuli for as long as they wished before making a size judgment, and could feel the lines and the appropriate ruler simultaneously if they wished. After making a height (or width) judgment, the subjects were told to feel the line again before judging the other dimension (height or width). The subjects were told that they had to keep their index fingers in contact with the patterns at all times. Thus, they were prohibited from attempting to trace directly between the endpoints of the curves when estimating this extent. Also, they were told to keep their arms elevated, since this has been shown to magnify the horizontal-vertical illusion with inverted-T and L shapes (Heller et al 1997). 


\subsection{Results and discussion}

Table 7 shows the results of the experiment. The presence of a strong illusion was indicated by larger size judgments for verticals $(M=7.7 \mathrm{~cm})$ than horizontals $(M=6.6 \mathrm{~cm})$. The effect of orientation was highly significant $\left(F_{1,22}=47.5, p<0.001\right)$, as was the effect of size $\left(F_{4,88}=367.3, p<0.001\right)$. However, the effect of group (ruler) failed to reach significance $\left(F_{1,22}=2.3, p=0.14\right)$. The main effects of trials and type of pattern were both marginal (both $p \mathrm{~s}>0.066$ ). The overall size estimates for the Ls $(M=7.4 \mathrm{~cm})$ were slightly larger than those for the curves $(M=6.9 \mathrm{~cm})$. There were significant interaction effects between pattern and size $(p<0.05)$ and between size and orientation $(p<0.001)$. The tests of simple effects of the interaction between pattern and size showed that pattern type mattered for the two largest stimuli (both $p$ s $<0.03$ ), but not for the smaller sizes. The curves were judged as slightly smaller than the Ls, but only for the two largest sizes of stimuli. The effect of orientation was significant for all sizes of stimuli, but the differences between height and width judgments were somewhat greater for the larger stimuli.

Table 7. Mean size judgments, standard deviations (SD) and percent error as a function of stimulus shape, size, and horizontal (H) and vertical (V) orientations in experiment 8 for the group with two tangible rulers (horizontal and vertical) and the group with a single horizontal tangible ruler.

\begin{tabular}{|c|c|c|c|c|c|c|c|c|c|}
\hline \multirow{3}{*}{\multicolumn{2}{|c|}{$\begin{array}{l}\text { Stimulus } \\
\text { size } / \mathrm{cm}\end{array}$}} & \multicolumn{4}{|c|}{ Horizontal and vertical tangible ruler group } & \multicolumn{4}{|c|}{ Horizontal tangible ruler group } \\
\hline & & \multicolumn{2}{|c|}{ L shape } & \multicolumn{2}{|c|}{ Convex curve } & \multicolumn{2}{|c|}{ L shape } & \multicolumn{2}{|c|}{ Convex curve } \\
\hline & & $\mathrm{H}$ & V & $\mathrm{H}$ & $\mathrm{V}$ & $\mathrm{H}$ & $\mathrm{V}$ & $\mathrm{H}$ & $\mathrm{V}$ \\
\hline 2.5 & $\begin{array}{l}M \\
\text { SD } \\
\% \text { error }\end{array}$ & $\begin{array}{r}2.5 \\
0.6 \\
-0.1\end{array}$ & $\begin{array}{r}3.2 \\
0.5 \\
26.5\end{array}$ & $\begin{array}{r}2.3 \\
0.5 \\
-6.5\end{array}$ & $\begin{array}{l}2.7 \\
0.7 \\
9.8\end{array}$ & $\begin{array}{l}2.7 \\
0.5 \\
8.5\end{array}$ & $\begin{array}{r}3.0 \\
0.6 \\
19.8\end{array}$ & $\begin{array}{r}2.8 \\
1.4 \\
13.7\end{array}$ & $\begin{array}{r}3.0 \\
1.1 \\
21.5\end{array}$ \\
\hline 5.1 & $\begin{array}{l}M \\
\text { SD } \\
\% \text { error }\end{array}$ & $\begin{array}{r}4.4 \\
1.2 \\
-12.8\end{array}$ & $\begin{array}{l}5.3 \\
0.8 \\
3.3\end{array}$ & $\begin{array}{r}4.0 \\
1.0 \\
-22.4\end{array}$ & $\begin{array}{r}4.9 \\
1.2 \\
-3.8\end{array}$ & $\begin{array}{r}5.0 \\
1.2 \\
-1.2\end{array}$ & $\begin{array}{l}5.4 \\
0.9 \\
5.8\end{array}$ & $\begin{array}{r}5.1 \\
1.5 \\
-0.7\end{array}$ & $\begin{array}{r}5.9 \\
2.1 \\
15.0\end{array}$ \\
\hline 7.6 & $\begin{array}{l}M \\
\text { SD } \\
\% \text { error }\end{array}$ & $\begin{array}{r}6.9 \\
1.4 \\
-9.2\end{array}$ & $\begin{array}{r}7.6 \\
1.6 \\
-0.6\end{array}$ & $\begin{array}{r}5.9 \\
2.0 \\
-21.9\end{array}$ & $\begin{array}{r}7.2 \\
1.6 \\
-5.9\end{array}$ & $\begin{array}{r}7.0 \\
1.8 \\
-7.6\end{array}$ & $\begin{array}{l}8.3 \\
1.8 \\
9.4\end{array}$ & $\begin{array}{r}7.4 \\
1.5 \\
-3.1\end{array}$ & $\begin{array}{l}8.1 \\
2.4 \\
7.1\end{array}$ \\
\hline 10.2 & $\begin{array}{l}M \\
\text { SD } \\
\% \text { error }\end{array}$ & $\begin{array}{r}8.9 \\
2.0 \\
-12.5\end{array}$ & $\begin{array}{r}10.1 \\
2.3 \\
-0.9\end{array}$ & $\begin{array}{r}7.4 \\
2.1 \\
-27.5\end{array}$ & $\begin{array}{r}9.3 \\
2.8 \\
-8.9\end{array}$ & $\begin{array}{r}9.3 \\
2.4 \\
-8.8\end{array}$ & $\begin{array}{r}11.1 \\
1.9 \\
8.8\end{array}$ & $\begin{array}{r}9.3 \\
2.0 \\
-9.0\end{array}$ & $\begin{array}{r}10.6 \\
2.3 \\
4.0\end{array}$ \\
\hline 12.7 & $\begin{array}{l}M \\
\text { SD } \\
\% \text { error }\end{array}$ & $\begin{array}{r}10.4 \\
3.0 \\
-18.3\end{array}$ & $\begin{array}{r}12.0 \\
2.4 \\
-5.8\end{array}$ & $\begin{array}{r}8.9 \\
2.9 \\
-30.1\end{array}$ & $\begin{array}{r}10.8 \\
3.2 \\
-15.0\end{array}$ & $\begin{array}{r}11.1 \\
2.5 \\
-12.2\end{array}$ & $\begin{array}{r}13.0 \\
2.4 \\
2.0\end{array}$ & $\begin{array}{r}10.9 \\
2.0 \\
-14.1\end{array}$ & $\begin{array}{r}12.9 \\
2.2 \\
1.2\end{array}$ \\
\hline
\end{tabular}

Note: Percent error scores are obtained by subtracting the appropriate standard size from the subjects' size judgments and dividing by the standard. This yields positive percent error scores for overestimates and negative percent error scores for underestimates.

The results of this experiment are consistent with the idea that shape distortion occurs when subjects feel curves. An examination of table 7 shows that the subjects often underestimated the horizontal widths of the curves and overestimated heights when compared with widths. This shape distortion is a variant of the horizontalvertical illusion, and could help explain some of the error patterns that have been found for perceived extent in the earlier experiments reported here. The nonsignificant main effect of pattern indicates similar illusory distortion in Ls and convex curves. If anything, the illusion appeared somewhat greater for the convex curves, especially in the two-ruler group (see table 7). 
It should be noted that the strength of the horizontal-vertical illusion may be considered with respect to the size of the standard stimulus being judged. Thus, a $1 \mathrm{~cm}$ overestimation of height with respect to width would not represent the same magnitude of error when the stimulus is $2.5 \mathrm{~cm}$ as opposed to a stimulus of $10.2 \mathrm{~cm}$. Consequently, the obtained effect of size in the ANOVA on size judgments may be suspect. The data were transformed to produce percent error scores. The percent error transformation was accomplished by subtracting the appropriate true standard from each size estimate and dividing by the standard. This yields negative values for underestimations and positive values for overestimations of extent. An ANOVA on percent error scores yielded significant effects of orientation, owing to underestimation of horizontals $(M=-9.8 \%)$ and overestimation of verticals $(M=4.7 \%) \quad\left(F_{1,22}=51.5\right.$, $p<0.001)$, and the effect of size was also highly significant $\left(F_{4,88}=21.6, p<0.001\right)$. However, the interaction between size and orientation failed to reach significance $(F<1)$. This means that the illusion was present at robust levels throughout. None of the other main effects or interactions reached significance (all $p \mathrm{~s}>0.088$ ).

\section{General discussion}

The results of the present experiments indicate that curved lines are perceived as shorter than straight lines, and they also yielded underestimation of the distance between endpoints. These results were found for blind and for sighted subjects. The effect of curvature on length estimates is relatively robust. Similar performance for the sighted and visually impaired participants means that visual experience is not critical for this aspect of the understanding of space. If anything, the early-blind subjects tended to show smaller systematic underestimation of the greater extents (see table 2).

The data also indicate that, while curved lines tend to induce misperception of extent, this may be affected by the quantity of haptic exploration and is scale-dependent. The presence of a horizontal-vertical illusion was indicated by overestimation of verticals and underestimation of horizontals in experiment 8. Insufficient exploration of stimuli could sometimes lead to greater variability of judgments. Thus, increased tracing yielded accuracy in size estimates in experiment 3. In the unlimited trace group of experiment 3, subjects traced the straight lines more than the curved ones. Though perception is normally veridical and accurate (eg Gibson 1966), accuracy still depends upon the choice of appropriate perceptual exploratory strategies. Inadequate examination of stimuli will often magnify response variability. Whatever the explanation, the results are not likely to be explained as deriving from the use of the right hand for tracing and the left hand for size estimates. Moreover, the results are not limited to simultaneous exploration of the curves and tangible ruler (experiments 1 and 2), since they occurred with sequential, immediate-size estimates (eg experiments $3-7$ ). The results are consistent with those reported by Faineteau et al (2005).

Curves are subject to illusory misperception, and showed a horizontal-vertical illusion in experiment 8 . The illusion is relatively robust, and likely to influence judgments or semicircles as well as curves with equal width and height. However, future research will be needed to clarify causal factors. Thus, a failure to find an effect of frontal placement in experiment 7 might be consistent with a configurational explanation of the illusion. Note, however, that the subjects in experiment 7 judged the diameters of the curves, and not their heights. Height judgments may be more susceptible to the effects of a frontal placement (but see Faineteau et al 2005).

However, it is still possible that perceptual distortion could derive from nonoptimal exploration, since subjects were limited to tracing with the index finger in most of the experiments reported here. The use of two hands has been shown to reduce perceptual distortion in the haptic Müller-Lyer illusion (Heller et al 2005). This explanation does not fit with the results of experiment 6 , since subjects showed a similar pattern of 
distortion, despite being allowed to use both hands to feel the stimuli. The subjects in that experiment were told that they could use any method that they wished to feel the patterns, but they still showed a different pattern of responses to curves and straight lines. However, it is important to qualify these comments, since not all sizes of curves were misjudged. The subjects in experiment 6 showed underestimation of the longest curves, but not the shortest stimuli. Increases in size tend to magnify perceptual error, a result consistent with the reports by Faineteau et al $(2003,2005)$.

From an ecological perspective, one would expect that observers should be able to make accurate size estimates, at least if the judgments were relative rather than absolute. However, in the present study we asked participants to make absolute size judgments. Perceptual error is likely to derive from poor 'viewing' conditions, or from impoverished stimuli (eg Gibson 1966). Moreover, one might expect reduced perceptual accuracy when subjects are limited to the use of a single sensory system, since from some theoretical perspectives perception is normally multimodal. According to Gibson (1966, page 313), illusions derive from the information present in drawings. Gibson argued that judgments of extent in lines derive from the entire configuration. Also, it is important to note that the curves in the present experiments were all essentially two-dimensional and comprised raised-line drawings. It is not known whether or not curves are judged any differently in the form of drawings or solids. However, the St Louis Arch is a curved three-dimensional solid structure, yet people routinely misjudge the height and perceive it to be greater than the width. A similar haptic horizontal - vertical illusion was obtained with convex curves in experiment 8 .

While it was possible to reduce perceptual error in some of the present experiments, the tendency to underestimate the distance between the endpoints of curved lines was relatively persistent. It remains to be seen if these errors can be reduced any further with greater experience or other, perhaps more optimal conditions of stimulus presentation. Note that the effect of curvature was greatly diminished when subjects made judgments of line length (experiment 2), rather than the distance between the endpoints of curves. One might very well argue that these distance judgments (between endpoints) represent higher-level cognitive computations, rather than mere perceptual judgments. This follows, since these distances were not felt directly while scanning. Subjects in the present experiments were not permitted to trace between the endpoints of lines when making these judgments. They were always required to keep their index fingers in contact with the curves. Clearly, much more needs to be done in this research area.

The results of the present experiments are relevant to practical applications for graphics and maps for people who are visually impaired. Raised-line map configurations often use curves, and it is obvious that a single trace may not always allow veridical judgments of extent. With complex configurations, including many curves varying in height, repeated tracing can sometimes prompt increased distortion of extent. Misperception of extent is clearly scale-related, with greater distortion for larger configurations. Awareness of these possibilities may be important for instructing blind people in the most effective methods for examining graphics and for the production of useful tangible displays. Larger is sometimes, but not always, 'better'.

One normally thinks of sensory aftereffects, such as curvature aftereffects, as major contributors to perceptual error and the misperception of stimulus attributes, such as extent. It is very conceivable that these curvature aftereffects contributed to misperception of extent in some of the present experiments. However, it bears repeating that subjects traced the straight lines more than the curved ones, and still underestimated the diameters of the semicircles in experiment 3. Also, a curvature-aftereffect explanation of the data is unlikely to explain the results of experiments 4, 5, and 8. Increases in tracing had no effect on the judged height of curves in experiment 4. Any explanation of the 
results involving curvature aftereffects and phenomenal 'flattening' of curves seems implausible, given these data and a clear horizontal-vertical illusion in experiment 8 . Increased tracing of curves aided performance by participants in experiment 3 by enlarging the size estimates of the larger semicircles. It is important that radial tracing may have contributed to overestimation of the heights of the curves relative to their widths in experiment 8 . Greater clarification of other relevant mechanisms will be the subject of further research.

Acknowledgments. This research was supported in part by NSF RUI grant BCS-0317293 from the program in Perception, Action and Cognition. We are grateful to Smita Srivastava, Michelle Kerr, Amy Matz, Crystal Kranz, Mark Baker, Cassie Ambuehl, and Jessica Campbell for assistance with data collection and analyses.

\section{References}

Appelle S, 1991 "Haptic perception of form: Activity and stimulus attributes", in The Psychology of Touch Eds A Heller, W Schiff (Hillsdale, NJ: Lawrence Erlbaum Associates) pp 169-188

Coren S, Girgus J S, 1978 Seeing is Deceiving: The Psychology of Visual Illusions (Hillsdale, NJ: Lawrence Erlbaum Associates)

Davidson P W, 1972 "Haptic judgments of curvature by blind and sighted humans" Journal of Experimental Psychology 93 43-55

Easton R D, Falzett M, 1978 "Finger pressure during curved contours: Implications for a visual dominance phenomenon" Perception \& Psychophysics $24145-153$

Faineteau H, Gentaz E, Viviani P, 2003 "The kinesthetic judgment of Euclidean distance: A study of the detour effect" Experimental Brain Research $152166-172$

Faineteau H, Gentaz E, Viviani P, 2005 "Factors affecting the size of the detour effect in the kinesthetic perception of Euclidean distance" Experimental Brain Research 163 503-514

Gibson J J, 1933 "Adaptation, after-effect and contrast in the perception of curved lines" Journal of Experimental Psychology $161-31$

Gibson J J, 1966 The Senses Considered as Perceptual Systems (Boston, MA: Houghton Mifflin)

Heelan P A, 1983 Space-perception and the Philosophy of Science (Berkeley, CA: University of California Press)

Heller M A, 1992 "The effect of orientation on tactual braille recognition: Optimal 'touching positions" " Perception \& Psychophysics $51549-556$

Heller M A, Brackett D D, Salik S S, Scroggs E, Green S, 2003 "Objects, raised-lines and the haptic horizontal-vertical illusion" Quarterly Journal of Experimental Psychology A 56891 -907

Heller M A, Brackett D D, Wilson K, Yoneyama K, Boyer A, Steffen H, 2002 "The haptic Müller-Lyer illusion in sighted and blind people" Perception $311263-1274$

Heller M A, Calcaterra J A, Burson L L, Green S L, 1997 "The tactual horizontal-vertical illusion depends on radial motion of the entire arm" Perception \& Psychophysics 59 1297-1331

Heller M A, McCarthy M, Schultz J, Greene J, Shanley M, Clark A, Skoczylas S, Prociuk J, 2005 "The influence of exploration mode, orientation, and configuration on the haptic Müller-Lyer illusion"” Perception 341475 - 1500

Kappers A M L, 1999 "Large systematic deviations in the haptic perception of parallelity" Perception 281001 - 1012

Kappers A M L, 2003 "Large systematic deviations in a bimanual parallelity task: further analysis of contributing factors" Acta Psychologica 114131 - 145

Kappers A M L, Koenderink J J, 1999 "Haptic perception of spatial relations" Perception 28 $781-795$

Pont S C, Kappers A M L, Koenderink J J, 1997 "Haptic curvature discrimination at several regions of the hand" Perception \& Psychophysics 59 1225-1240

Vogels I M L C, Kappers A M L, Koenderink J J, 1996 "Haptic aftereffect of curved surfaces" Perception $25109-119$

Vogels I M L C, Kappers A M L, Koenderink J J, 1997 "Investigation into the origin of the haptic aftereffect of curved surfaces" Perception $26101-117$

Zuidhoek S, Kappers A M L, Lubbe R van der, Postma A, 2003 "Delay improves performance on a haptic spatial matching task" Experimental Brain Research 149320 - 330 


\section{PERTEPTION}

VOLUME 372008

www.perceptionweb.com

Conditions of use. This article may be downloaded from the Perception website for personal research by members of subscribing organisations. Authors are entitled to distribute their own article (in printed form or by e-mail) to up to 50 people. This PDF may not be placed on any website (or other online distribution system) without permission of the publisher. 